\title{
JUURNAL.RU
}

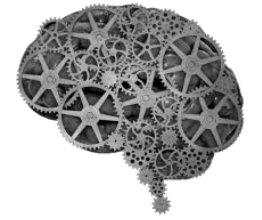

COMPANY GROUP "INTELLEKT"

Гаврилов Н.О. Национальный исследовательский университет «Московский институт электронной техники»

Зеленоград, Россия

doi: 10.18411/lj2016-7-2-03

idsp 000001: lj2016-16-2-03

\section{Разработка программного обеспечения подсистемы преобразования иерархического представления схем}

Одной из самых ключевых функций любой САПР СБИС является моделирование разработанной схемы. Именно правильность работы полученной схемы определяет то, каким продукт будет в конечном итоге.

Перед тем как провести моделирование схемы, нужно раскрыть ее до базиса библиотечных элементов, так как задержки модульных элементов можно рассчитать зная какие библиотечные элементы в него входят. Информация о задержках и времени переключения хранятся только в библиотечных элементах.

Для того, чтобы провести раскрытие схемы нужно составить ее иерархическую модель для выявления принадлежности модулей. Произвести обход предлагается двумя стандартными методами, это обход дерева сверху вниз и снизу в верх.

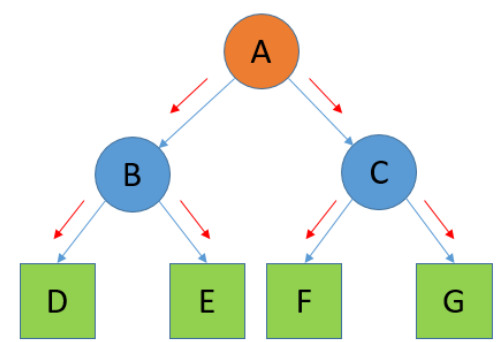

Рис.1 Обход дерева элементов сверху вниз

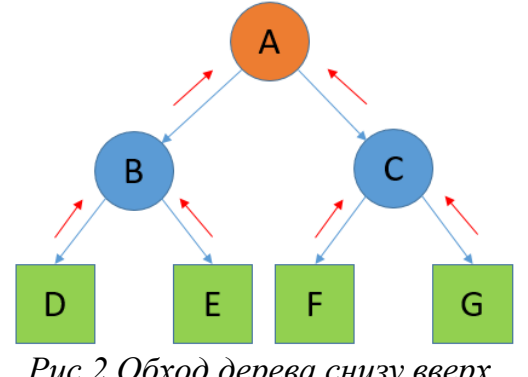

Pис.2 Обход дерева снизу вверх 
Раскрытие производимое снизу вверх имеет особенность перезаписи текущего модуля. То есть если модуль встречается в схеме несколько раз, то на его раскрытие требуется 1 итерация, затем он всегда остается раскрытым. Это дает преимущество перед алгоритмом обхода дерева сверху вниз.

Примечание: текущий алгоритм будет работать быстрее стандартного в том случае, если существуют одинаковые модули на разных уровнях.

Рассмотрим на простом примере суть работы данного алгоритма:

Перед нами граф, вершинами которого являются либо библиотечные элементы (зеленые квадраты), либо модульные элементы (круги). Топ-модулем в данной схеме является вершина М (оранжевый круг), она содержит все остальные модули.

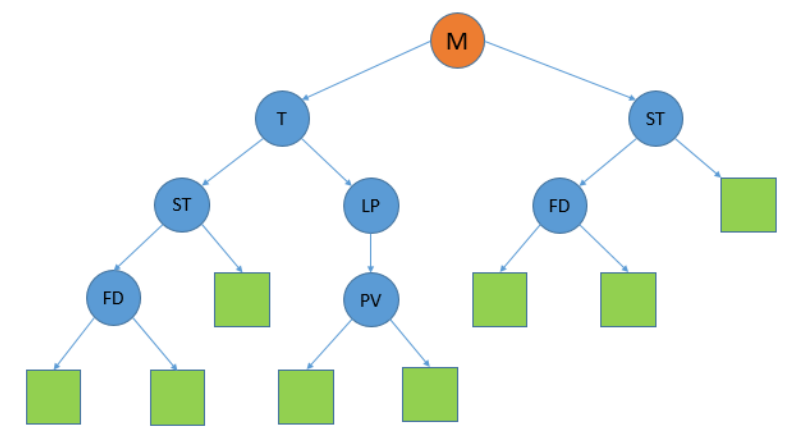

Рис.3 Иерархическое дерево элементов схемы.

Для обхода дерева элементов алгоритмом обхода дерева элементов сверхувнизу (pre-ordered)потребовалось 7 итераций.

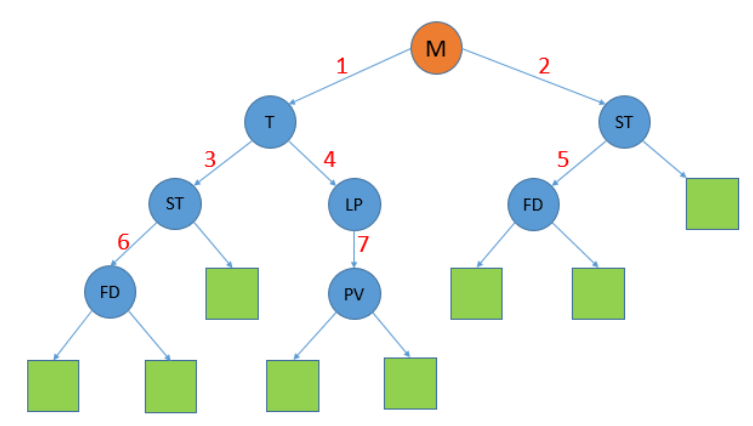

Рис.4 Количество итераций для обхода дерева элементов сверху-вниз.

Для обхода дерева элементов алгоритмом обхода дерева элементов снизувверх (post-ordered)потребовалось 6 итераций. 


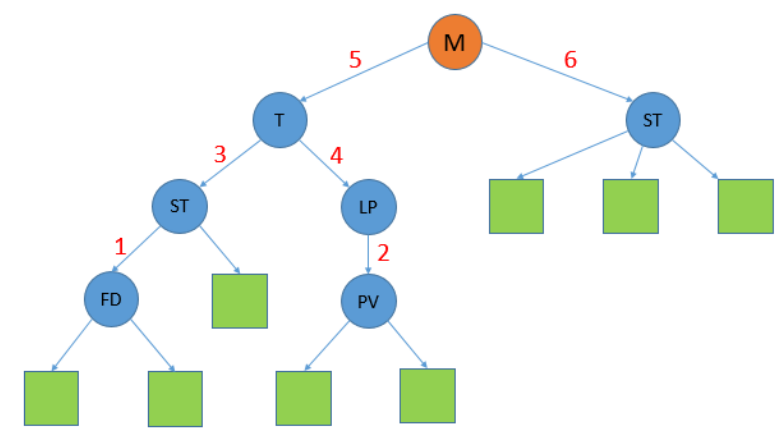

Рис.5 Количество итераџий для обхода дерева элементов снизу-вверх.

Количество итераций уменьшилось за счет того, что здесь есть дублированные модули, в нашем случае модуль ST. Для данного способа его нужно раскрыть всего один раз, за счет этого увеличивается эффективность работы алгоритма.

Так как схемы в нашей жизни зачастую имеют многократно повторяющиеся модули, то применение данного алгоритма несет за собой уменьшение количества итераций для этого, а из этого следует уменьшение работы программы.

При увеличении количества модулей, степень вложенности растет, а значит количество итераций уменьшается это видно на рис.3.3. Примерами для выявления зависимости были взяты случайные графы, с разной степенью вложенности. Степень вложенности напрямую зависела от количества модулей в схеме.

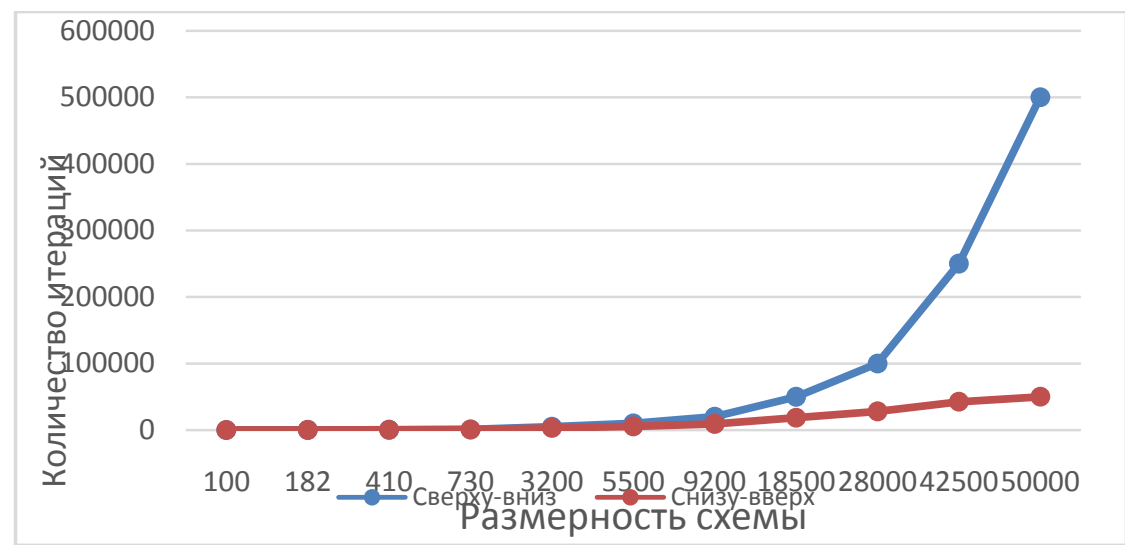

Рис.6 График зависимости количества итераций от разной степени вложенности при работе разных алгоритмов. 
Прекрасно наблюдается зависимость и преимущество работы алгоритма обхода снизу-вверх над графами, которые имеют высокую степень вложенности.

Вывод: при высокой степени вложенности графа, то есть при большом количестве одинаковых модулей в схеме, алгоритм обхода дерева элементов схемы сверху-вниз показал себя на много эффективнее.

\section{Литература:}

1. Роберт Седжвик. Алгоритмы на $\mathrm{C}++$. Фундаментальные алгоритмы и структуры данных. 2013. - 1056 с.

2. Мазалов В.В. Математическая теория игр и приложения.2012. 446 с. ISBN 978-5-8114-1025-5.

3. Бьярне Страуструп. Программирование: принципы и практика использования $\mathrm{C}++$, исправленное издание, 2011. 